\title{
Molecular targets for modulating the protein translation vital to proteostasis and neuron degeneration in Parkinson's disease
}

\author{
Zhi Dong Zhou ${ }^{1,3^{*}}$ (D) Thevapriya Selvaratnam", Ji Chao Tristan Lee ${ }^{1}$, Yin Xia Chao ${ }^{1}$ and Eng-King Tan ${ }^{1,2,3^{*}}$
}

\begin{abstract}
Parkinson's disease (PD) is the most common neurodegenerative movement disorder, which is characterized by the progressive loss of dopaminergic neurons in the Substantia Nigra pars compacta concomitant with Lewy body formation in affected brain areas. The detailed pathogenic mechanisms underlying the selective loss of dopaminergic neurons in PD are unclear, and no drugs or treatments have been developed to alleviate progressive dopaminergic neuron degeneration in PD. However, the formation of a-synuclein-positive protein aggregates in Lewy body has been identified as a common pathological feature of PD, possibly stemming from the consequence of protein misfolding and dysfunctional proteostasis. Proteostasis is the mechanism for maintaining protein homeostasis via modulation of protein translation, enhancement of chaperone capacity and the prompt clearance of misfolded protein by the ubiquitin proteasome system and autophagy. Deregulated protein translation and impaired capacities of chaperone or protein degradation can disturb proteostasis processes, leading to pathological protein aggregation and neurodegeneration in PD. In recent years, multiple molecular targets in the modulation of protein translation vital to proteostasis and dopaminergic neuron degeneration have been identified. The potential pathophysiological and therapeutic significance of these molecular targets to neurodegeneration in PD is highlighted.
\end{abstract}

Keywords: Molecular targets, Neuron degeneration, Parkinson's disease, Protein aggregation, Protein translation, Proteostasis

\section{Background}

Parkinson's disease (PD) is the second most common neurodegenerative disorder with an incidence rate of $1 \%$ of the population over the age of 60 [1]. Furthermore, it is estimated that the number of individuals afflicted with PD will double by 2030 [2]. The pathological features of the disorder have been established as stemming from the selective and progressive degeneration of dopamine (DA) neurons in the Substantia Nigra pars compacta (SN) as well as the formation of protein inclusions known as Lewy bodies (LBs) in affected brain areas [3]. The progressive degeneration of DA neurons in the SN leads to a significant depletion of DA content in PD afflicted brains, which contribute to the onset of PD clinical symptoms, including tremors, akinesia,

\footnotetext{
* Correspondence: zhidong_zhou@nni.com.sg; Tan.eng.king@sgh.com.sg 1 Department of Research, National Neuroscience Institute, 11 Jalan Tan Tock Seng, Singapore 308433, Singapore

Full list of author information is available at the end of the article
}

bradykinesia and stiffness [4]. Epidemiological studies show that PD arises as largely sporadic PD (SPD) in nature, and their exact underlying pathogenesis is still unclear. However, the onset of fewer familial forms of PD (FPD) can be induced by mutations or variations of a dozen or more genes, including $\alpha$-synuclein ( $\alpha$-syn) [5], Parkin [6], PINK1 [7], DJ-1 [8], FBXO7 [9], CHCHD2 [10] and LRRK2 [11]. Currently, PD is still an incurable neurodegenerative disorder, and L-DOPA replacement therapy can transiently alleviate PD symptoms with no therapeutic effects on the progressive degeneration of DA neurons in PD patient brains.

One of the pathological features of PD is LB formation which are composed of multiple aggregated proteins in affected brain areas [12]. The formation of protein aggregates can be the pathological consequence of the disturbance and collapse of proteostasis [13]. Proteostasis refers to the maintenance of cellular protein homeostasis via multiple pathways that control the formation, 
folding, trafficking and clearance of proteins inside or outside the cell [14]. Proteostasis can be physiologically balanced by the upregulated levels and capabilities of chaperones, the enhanced efficiency in protein trafficking, the prompt clearance of misfolded proteins by ubiquitin proteasome system (UPS) and autophagy as well as the fine control of protein biogenesis [13] (Fig. 1). The maintenance of proteostasis is vital to many human physiological events including development, healthy aging, stress resistance and protection against pathogen invasion [14]. However, pathological factors, such as gene mutations, environmental toxins and pathological aging, can increase oxidative stress, impair mitochondria functions, aggravate protein misfolding and impair protective mechanisms, which will lead to disturbed and imbalanced proteostasis and cell demise (Fig. 2). Disturbed proteostasis inducing deleterious protein aggregation is relevant to the pathogenesis of various human disorders including cancer, obesity, PD and other human neurodegenerative disorders [15]. The primary modulation point to maintain the proteostasis is to exquisitely control the protein translation and biogenesis. This can be accomplished via kinase-induced phosphorylation and phosphatase-induced dephosphorylation of multiple ribosomal proteins, translation initiation factors and elongation factors indispensable for protein biogenesis (Fig. 3). The current review summarizes and discusses several identified molecular targets in the pathway for modulating protein translation vital to proteostasis and neuron degeneration in PD.

The protein translation process in eukaryotic cells includes three respective stages: translation initiation, elongation and termination [16]. The translation initiation process is the rate-determining step, which is controlled and coordinated by multiple eukaryotic initiation factors (eIFs) [17]. The eIFs play multiple roles in protein translation from activation of mRNA to the assembly of functional ribosomal subunits [18]. In principle, protein translation can be divided into two groups: cap-dependent and cap-independent mRNA translation [19]. In short, cap-dependent mRNA translation initiation occurs with the activation and circularization of mature mRNA and formation of a preinitiation complex (PIC) consisting of multiple eIFs and 40s ribosomal subunit (Fig. 3) [20, 21]. PIC can bind to the $5^{\prime}-\mathrm{m}^{7} \mathrm{GpppX}$ cap structure of mature mRNA to search for the starting codon in the mRNA 5' untranslated region (5'UTR) for the initiation of translation [22]. Consequently, the $60 \mathrm{~S}$ ribosomal subunit is recruited concomitantly with the release of eIFs, leading to the formation of the $80 \mathrm{~s}$

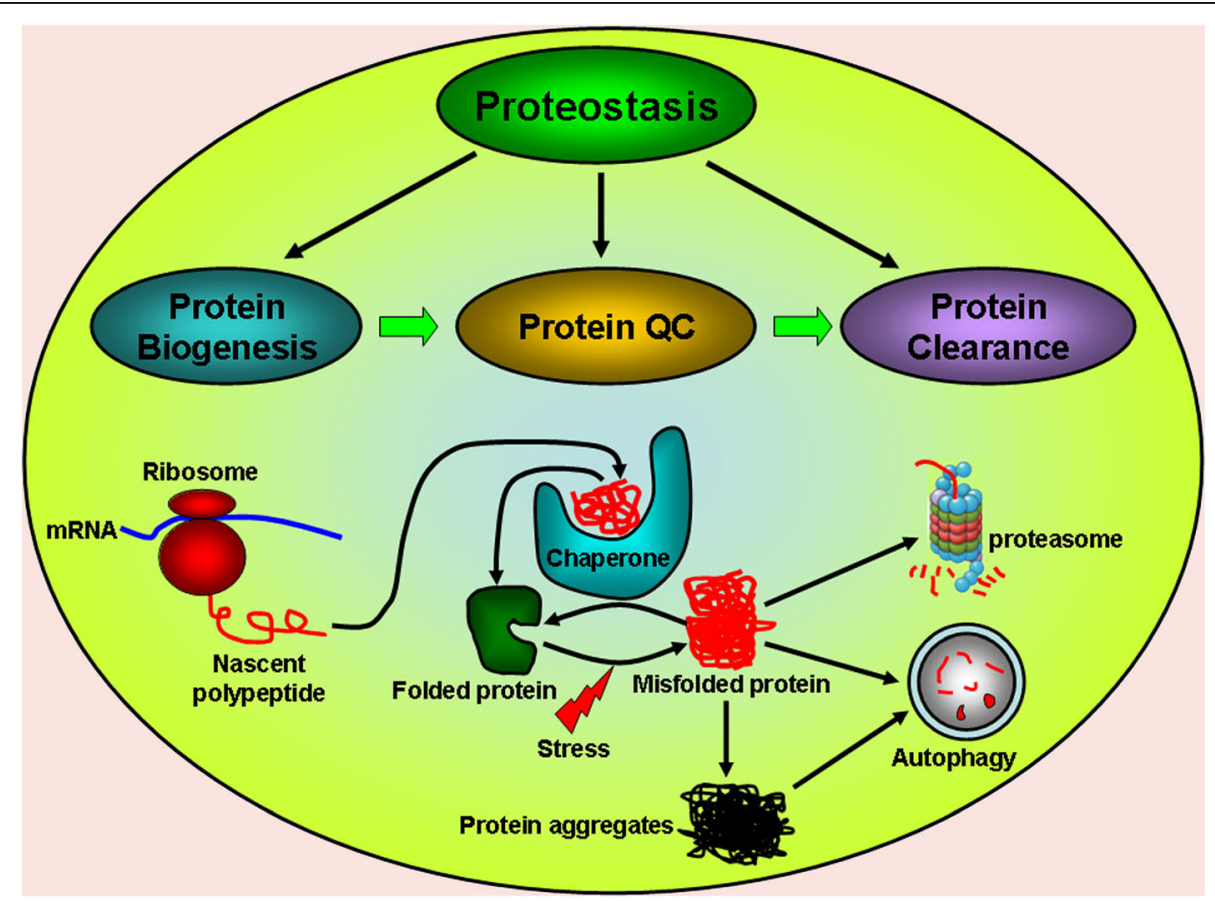

Fig. 1 Molecular mechanisms for proteostasis maintenance Proteostasis can be maintained via three distinct and interlinked mechanisms, including the modulation of protein biogenesis, enhancement of chaperone capacity and prompt clearance of misfolded protein by UPS and autophagy. The ribosomal synthesis of nascent polypeptide is exquisitely modulated. The synthesized polypeptide can be folded into functional proteins with the assistance of chaperones. Chaperones can also function to refold stress-induced misfolded proteins. The misfolded protein can be cleared away by UPS and autophagy. However, the deregulated modulation of protein biogenesis and impairment of chaperone function, UPS and autophagy capacities can lead to disturbed proteostasis and protein aggregate formation 


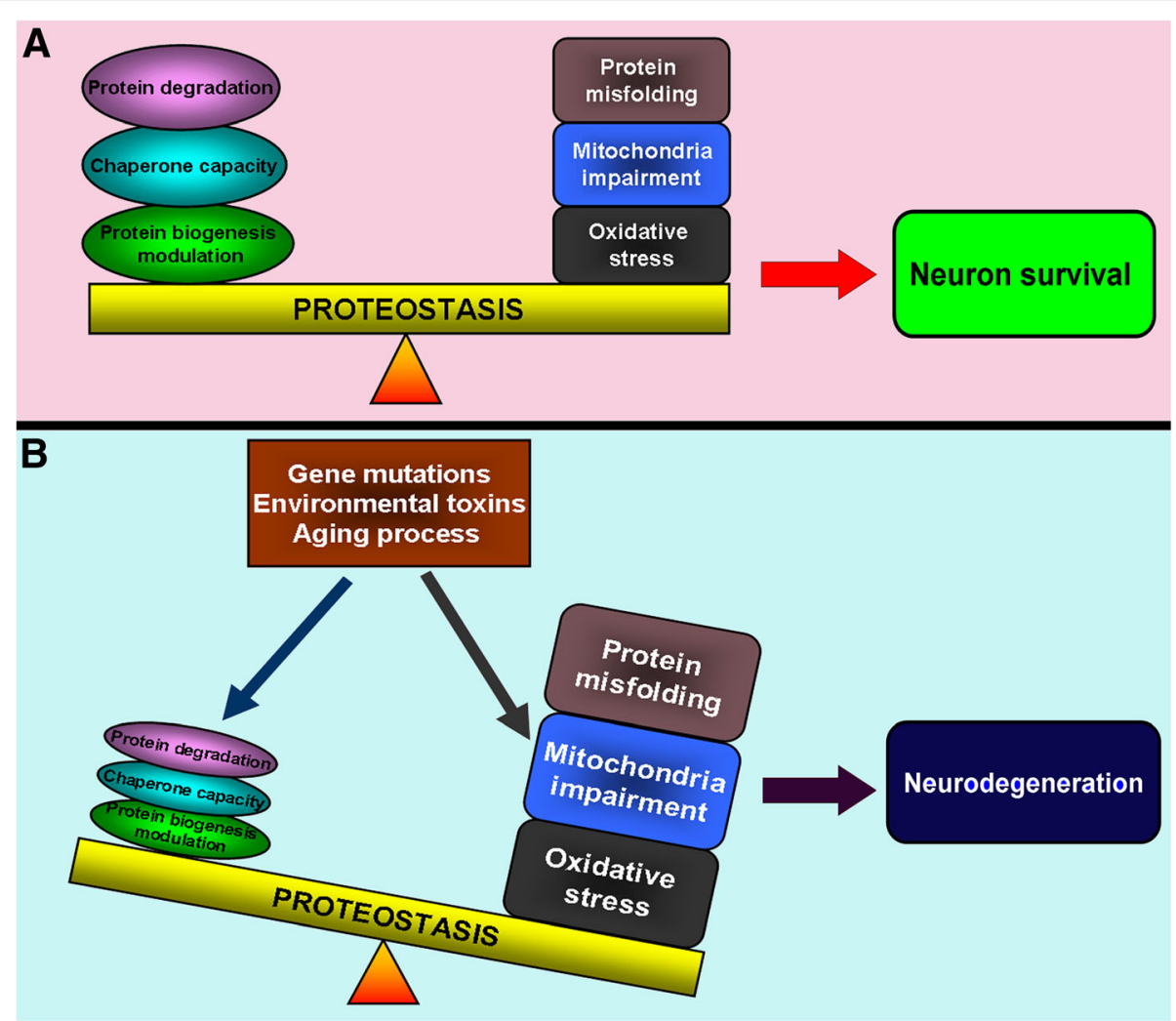

Fig. 2 Balance and imbalance of proteostasis implicated in PD pathogenesis Under physiological conditions, the modulation of protein biogenesis, chaperone capacity and protein degradation can counteract against deleterious factors and stress challenge-induced protein misfolding and proteostasis dysfunction (a). Under pathological conditions, such as PD-associated gene mutations, environmental toxin challenges and pathological aging, the protective capacities of the proteostasis mechanisms are impaired, whereas stress-induced protein misfolding, mitochondria impairment and oxidative stress are aggravated. This can lead to the imbalance of proteostasis and protein aggregation, contributing to neurodegeneration in PD (b)

ribosome complex for translation [23]. Alternatively, $3-5 \%$ of translation initiation can occur in a cap-independent manner, where ribosomes and eIFs are recruited to interact with the internal ribosomal entry site (IRES) or the cap-independent translation element (CITE) in mRNA to initiate translation [24]. After the initiation stage, nascent polypeptide chains can be generated and elongated during the translation elongation stage facilitated by eukaryotic elongation factor 2 (eEF2) [25]. eEF2 functions to mediate the positioning of the appropriate aminoacyl-tRNA to the acceptor site of the ribosome (A site), where the innate peptidyltransferase activity of the 80 s ribosome will catalyze the formation of new peptide bonds between amino acids [26]. Furthermore, eEF2 promotes the translocation of the ribosome translation complex to the next codon in mRNA template to facilitate the elongation process $[27,28]$. When the ribosome complex reaches the stop codon in mRNA template, multiple translation release factors (RFs) are recruited to release the new-born polypeptide from the ribosome, and protein translation is terminated $[27,28]$.

\section{Main text}

Eukaryotic initiation factor 2 (elF2) as a molecular target in PD

eIF2 is the key factor for modulating protein translation at the translation initiation stage (Fig. 3) [29]. eIF2 is a heterotrimeric protein complex comprised of alpha, beta and gamma isoforms [30]. eIF2 is an essential initiation factor to interact with the initiator methionyl-tRNA $\left(\right.$ Met-tRNA ${ }_{i}^{\text {Met }}$ ) and GTP to form an active ternary complex, which is essential for cap-dependent translation initiation [19]. Aided by other eIFs including eIF1, eIF1A and eIF3, this ternary complex interacts with the 40s ribosome to form PIC for translation initiation [19]. Subsequently, recruited eIF5 (a GTPase-activating protein) can induce eIF2 to hydrolyze GTP, leading to the dissociation of eIF2-GDP from the initiation complex and the beginning of protein translation after further recruitment of the 60S ribosomal subunit (Fig. 3) [19]. However, eIF2B, a Guanine nucleotide exchange factor (GEF), can function to exchange GDP in the inactive GDP-eIF2 complex with GTP to form the active GTP-eIF2, which can be used for a new round of 


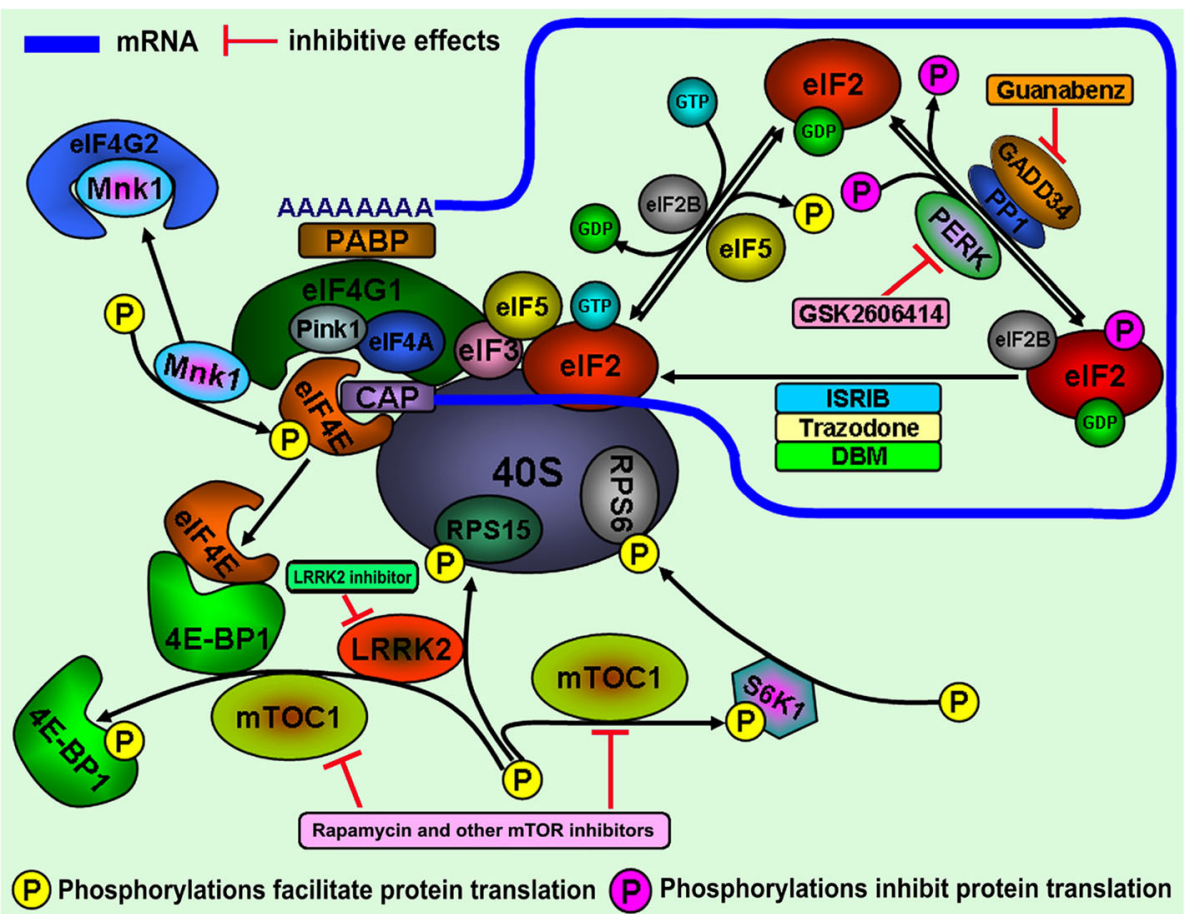

Fig. 3 Molecular targets in the modulation of protein translation initiation implicated in proteostasis and PD pathogenesis and therapy Ribosomal protein biogenesis can be exquisitely modulated on multiple targets mainly through the modulation of functions of protein targets via phosphorylation and dephosphorylation by kinases and phosphatases, respectively. Multiple factors including elF4G1, elF4E, elF4A, elF3, elF5, and elF2 take part in the formation of the translation initiation complex, which is vital for initiation of protein translation. The kinase-induced phosphorylation of elF4E, 4E-BP1, RPS15 and RPS6 will facilitate protein translation, which is supposed to be adverse to the maintenance of proteostasis under stress and implicated in PD pathogenesis. Mnk1 can phosphorylate elF4E to enhance its binding with elF4G1 to promote translation initiation, which can be abrogated by elF4G2 chelation. However, the function of elF4E can be inhibited by 4E-BP1 sequestration, which can be abrogated by LRRK2 and mTORC1 kinase-induced 4E-BP1 phosphorylation. LRRK2 kinase can also phosphorylate RPS15 to enhance protein translation, whereas mTORC1 kinase can phosphorylate S6K1. The phosphorylated S6K1 subsequently phosphorylates RPS6, which in turn promotes protein translation. LRRK2 and mTORC1 kinase inhibitors are supposed to have potential therapeutic effects against neurodegeneration in PD. On the other hand, the phosphorylation of elF2a by PERK kinases can inhibit protein biogenesis. However, GADD34 can direct PP1 to dephosphorylate eIF2a, which can restore protein translation. GBZ can block GADD34 to promote elF2a phosphorylation and arrest protein translation, whereas GSK2606414 can inhibit kinase-induced elF2a phosphorylation to recover protein biogenesis. ISRIB, Trazodone and DBM can function downstream of elF2a phosphorylation without influence on elF2a phosphorylation to promote protein translation. However, all three FDA-approved drugs (GBZ, Trazodone and DBM) claim to have protective capacities against neurodegeneration in PD

translation initiation (Fig. 3) [19]. The alpha component of eIF2 protein complex has a phosphorylation site at Serine (S) 51 that can be phosphorylated by various stress-relevant kinases (e.g., PERK, PKR and GCN2) [31]. Phosphorylated eIF2 has high affinity to bind with eIF2B and inhibit the Guanine nucleotide exchange capacity of eIF2B, leading to formation of the inactive ternary complex (phosphorylated eIF2-GDP-eIF2B) (Fig. 3) [32]. The inactivated ternary complex will be incapable of being assembled into functional PIC to initiate protein translation [33]. Therefore, stress-induced eIF2 $\alpha$ phosphorylation can lead to the transient shut down of global protein translation, thus providing a modulation mechanism for protein translation under stress [33]. However, stress induced eIF2 $\alpha$ phosphorylation can also up-regulate specific gene expressions. The translation of ATF4, a key transcriptional factor to mediate endoplasmic reticulum (ER) unfolded protein response (erUPR), can be activated under stress induced eIF2 $\alpha$ phosphorylation [34]. In mice liver, the translation of $\mathrm{C} /$ EBP $\alpha$ and $C / E B P \beta$ proteins was reported to be promoted by eIF2 $\alpha$ phosphorylation [35]. Furthermore, eIF2 $\alpha$ phosphorylation can activate cellular IRES elements to up-regulate IRES-mediated protein translation under a range of physiological circumstances [36]. The eIF2 $\alpha$ phosphorylation can be counteracted by GADD34 to abrogate the stress-induced global translation arrestment via directing protein phosphatase 1 (PP1) to dephosphorylate the phosphorylated eIF2 $\alpha$ as well as via its interaction with eIF2 $\alpha$ to form a ternary complex to promote post-stress translation recovery (Fig. 3) [37].

Previous studies have demonstrated that eIF2 and its interacting proteins are essential for physiological brain function and development [18, 38]. The phosphorylation 
of eIF2 $\alpha$-induced shutdown of global protein translation can be the consequence of protein misfolding-induced erUPR [32]. The deregulation of erUPR and imbalance between phosphorylation and dephosphorylation of eIF $2 \alpha$ is implicated in PD neuronal degeneration [32, 39]. The pathological accumulation of wild type (WT) and mutant $\alpha$-syn can activate erUPR in PD brains $[40,41]$. The accumulated $\alpha$-syn in ER can bind with GRP78/BiP, leading to activation of erUPR through the PERK-dependent pathway $[40,42]$. Furthermore the activation of erUPR will facilitate pathological $\alpha$-syn aggregation [41]. Similarly, the accumulated tau protein in ER can impair ER-associated degradation (ERAD), leading to activation of erUPR and subsequent pathological phosphorylation of Tau protein [43]. The phosphorylated PERK and eIF2 $\alpha$ have been detected in dopaminergic neurons in the SN of PD patients but not in healthy control cases [44]. The deregulated erUPR pathway and eIF2 $\alpha$ phosphorylation can also be observed in peripheral blood mononuclear cells (PBMCs) of SPD and FPD patients [45]. Furthermore, eIF2 $\alpha$ has been identified as a therapeutic target for PD [44]. The PERK kinase inhibitor GSK2606414 is demonstrated to prevent neuronal death in PINK1 and Parkin mutant flies [46]. Most recent findings demonstrate the neuroprotective capacity of GSK2606414 against PD-inducing neurotoxin-induced DA neuronal degeneration in a mouse PD model [47]. Although GSK2606414 is not suitable for applications to human PD patients due to its pancreatic toxicity [47], these findings indicate that targeting erUPR pathway and eIF2 $\alpha$ phosphorylation hold promise towards the prevention of neurodegeneration in PD. A second compound, integrated stress response inhibitor (ISRIB) with the capacity to bind to eIF2B to activate its GEF activity under eIF2 $\alpha$ phosphorylation [48], has been demonstrated to delay neurodegeneration in a prion mouse model [49]. However, the insoluble nature of ISRIB makes it difficult to be used in human patients [50]. In 2017, two FDA-approved drugs (Trazodone hydrochloride (Trazodone) and dibenzoylmethane (DBM)) with the capability to reverse eIF2 $\alpha$ phosphorylation-induced protein translation arrestment and protect against in vivo neuron degeneration were identified from a phenotypic screening study [51]. DBM has displayed neuroprotective functions in both in vitro and in vivo PD models [52]. However, in 1998, a 74-year-old woman with depression symptoms after losing her sister was prescribed Trazodone to improve her mood [53]. Just several months after Trazodone usage, she began exhibiting Parkinsonism symptoms [53]. This was not an isolated case of Trazodone-induced motor issues after periodic usage of Trazodone [54]. Thus far, the pharmacological targets of Trazodone and DBM are still largely unknown and caution needs to be taken when these drugs are prescribed to PD patients. The ISRIB Trazodone and DBM can alleviate the eIF2 $\alpha$ phosphorylation-induced protein translation arrestment without influencing the levels of phosphorylated eIF2 $\alpha$, suggesting that they function downstream of eIF $2 \alpha$ phosphorylation (Fig. 3) [50].

On the other hand, Guanabenz (GBZ), a FDA-approved antihypertensive drug, is identified to be neuroprotective with capability to inhibit GADD34, leading to subsequent promotion of eIF $2 \alpha$ phosphorylation, protein translation arrestment and maintenance of proteostasis [55-59]. GBZ can enhance eIF2 $\alpha$ phosphorylation and protect against stress induced DA neuron degeneration in various PD models in an ATF4- and Parkindependent manner [60]. Recently Sephin1, a GBZ derivative with specific GADD34 inhibition capability but lack of $\alpha 2$-adrenergic agonist activity, is developed to protect against neuron degeneration relevant to erUPR induced by accumulation of misfolded proteins [61]). However, findings from a recent study challenge the view that GBZ and Sephin1 can restore proteostasis via interfering with the dephosphorylation of phosphorylated eIF $2 \alpha$ protein [62]. GBZ can function independent on modulation of eIF $2 \alpha$ phosphorylation [63-65]. The GBZ has anti-inflammatory effects mediated by eIF $2 \alpha-$ dependent and eIF2 $\alpha$-independent mechanisms [63]. Furthermore GBZ can specifically inhibit the protein folding activity of the ribosome (PFAR), which is implicated in the pathogenesis of human neuron degenerative diseases [65]. The PFAR is referred to the function of rRNA of the large ribosomal subunit to facilitate protein folding [65]. GBZ can inhibit PFAR by competition with protein substrates for the common binding sites on the domain V of rRNA [64, 65]. The neuroprotective mechanisms of GBZ and Sephin1 dependent on modulation of eIF2 $\alpha$ phosphorylation and should be paid more attention and warrants further investigations.

Thus far, the three FDA-approved drugs (GBZ, Trazodone and DBM) exert opposing influences on eIF2 $\alpha$ phosphorylation-induced alterations of global protein translation. GBZ promotes the phosphorylation of eIF $2 \alpha$ and the inhibition of protein translation. Therefore, GBZ may relieve the stress-induced accumulation of misfolded proteins, protein aggregation, proteostasis disturbance and cell stress, leading to neuroprotective effects. Conversely, Trazodone and DBM work to inhibit the eIF $2 \alpha$ phosphorylation-induced protein translation arrestment, leading to neuroprotection as demonstrated in various in vitro and in vivo PD models [52]. They have opposing effects on eIF $2 \alpha$ phosphorylation-modulated protein translation, but all drugs have been claimed to be neuroprotective. These findings are interesting. The accumulated misfolded protein and protein aggregation can lead to the imbalance of proteostasis, which can be a stress challenge to cells (Fig. 2) [66]. 
Therefore, the arrestment of protein translation induced by eIF $2 \alpha$ phosphorylation under stress can help cells alleviate protein misfolding and aggregation. This mechanism may account for the GBZ-induced neuroprotective effects. However, the persistent activation of erUPR and prolonged arrestment of protein translation can also be detrimental to cells [67]. Therefore, the Trazodone- and DBM-induced release of arrested protein translation under eIF $2 \alpha$ phosphorylation can rescue neurons from prolonged and persistent erUPR-induced neurodegeneration. This mechanism may also account for GSK2606414- and ISRIB-induced neuroprotective effects. However, releasing the protein misfolding-induced arrestment of protein translation at an earlier stage may aggravate the deleterious protein aggregation and proteostasis disturbance, which can trigger neuron degeneration. This may account for the Trazodone-induced motor issues and Parkinsonism symptoms in selected individual patient cases. Further works are needed on drugs targeting erUPR pathway and eIF2 $\alpha$ phosphorylation-induced modulation of protein translation and proteostasis maintenance. Caution should be taken when these drugs are applied to PD patients with different etiologies and distinct disease stages of PD.

\section{Eukaryotic initiation factor 4G1 (elF4G1) as a molecular target in PD}

Eukaryotic initiation factor $4 \mathrm{~F}$ (eIF4F) is a complex of multiple initiation factors, including the eIF4A and its cofactors eIF4B, eIF4E and eIF4G1 (Fig. 3) [68]. The eIF4F complex binds to the $5^{\prime}-\mathrm{m}^{7} \mathrm{GpppX}$ cap structure of the mRNA template while the poly-A binding protein (PABP) can bind to the poly-A tail of the mRNA, resulting in the circularization of the mRNA (Fig. 3) [69]. The eIF4F and mRNA cap complex then initiates protein translation by recruiting the PIC to the cap complex [70]. In the eIF4F complex, eIF4G1 acts as the main scaffold, binding to eIF4E, eIF4A and eIF3e as well as other molecules, such as PABP and the ribosome subunit (Fig. 3) [70]. When the availability of eIF4E is limited, eIF4G1 can initiate cap-independent translation through the formation of eIF4G1/eIF4A complexes and the recruitment of IRES-containing mRNA [71]. In humans, the overexpression of eIF4G1 is implicated in cancer and oncogenesis [72], whereas In yeast and nematodes eIF4G1 is found to be vital to organism development, wherein knock out of eIF4G1 is detrimental [73]. In addition to the down regulation of overall translation, inhibition of eIF4G1 alters the stoichiometry of mRNA translation supporting expression of genes vital to stress response in C. elegans [74]. The inhibition of eIF4G1 expression in adult stage extends the lifespan of C. elegans [74].
Recently, mutations of eIF4G1 were found to be linked to the pathogenesis of DA neuron degeneration in FPD. A genome-wide analysis study (GWAS) reported by Chartier-Harlin revealed the presence of eIF4G1 missense mutations p.Ala502Val (A502V) and p.Arg1205His $(\mathrm{R} 1205 \mathrm{H})$ in a French family and seven other PD-afflicted families from different countries but was absent in 4050 healthy controls [75]. Whole-genome sequencing among Americans also verified the presence of the R1205H eIF4G1 mutation in FPD patients [76]. Other variants of eIF4G1 identified in FPD include p.Gly686Cys (G686C), p.Ser1164Arg (S1164R) and p.Arg1197Trp (R1197W) [77-81]. However, follow-up studies carried out in a larger European cohort have questioned the causality of the R1205H eIF4G1 variant with PD onset [77-81]. Other novel but rare potential PD-linked eIF4G1 variants identified in these studies include p.Thr318Ile, p.Val541Gly, p.Gly698Ala, p.Pro4 86Ser [79], p.A425V, p.A428M, p.V541G, p.P486S, indels pE525del, pG466_A468del [76] and E462delInsGK [78]. Similar to the R1205H mutation, the eIF4G1 variants p.M432 V, p.A550P, p.P1229A, and p.L1233P are detected in both control and PD cases [78]. The E462d elInsGK variant was observed to be segregated in two PD siblings [78]. Moreover, studies in other ethnic groups reveal the eIF4G1 variants to be extremely rare in PD patients and negative for the prevalent eIF4G1 variants in PD patients of Asia [82-84], South Africa [85] and Greek ethnicities [86]. Collectively, these conflicting reports suggest that the mutations in the eIF4G1 gene are likely to be benign polymorphisms or are linked to FPD with an extremely rare prevalence rate of less than $1 \%$ of PD incidence worldwide [76, 80].

Nevertheless, in vitro studies suggest the potential pathological role of eIF4G1 mutants in PD pathogenesis. It is identified that the eIF4G1 A502V variant obstructs the binding of eIF4G1 to eIF4E, thereby interfering with the recruitment of mRNA to the ribosome and subsequent cap-dependent translation [75]. Similarly, the eIF4G R1205H variant hinders the binding of eIF4G1 to eIF3, affecting interactions among mRNA, eIF4F cap binding complex and 40s ribosomal subunit [75]. Apart from this, the eIF4G1 gene is revealed to be genetically and functionally associated with other PD genes, further elaborating its potential pathological roles in PD. The overexpression of eIF4G1 or TIF4631 (the yeast homo$\log$ of eIF4G1) was found to alleviate $\alpha$-syn toxicity in a yeast PD model [87]. However, overexpression of the R1205H mutant eIF4G1 impaired its capacity to inhibit $\alpha$-syn-induced toxicity [87]. Another PD-relevant gene pathologically linked to eIF4G1 gene is VPS35, a protein associated with the retrograde transport of proteins from the endosome to the trans-Golgi network. Mutations of VPS35 have been identified to be linked to autosomal 
dominant PD [88]. It was demonstrated that, when protein translation was influenced by the upregulated level of TIF4631, yeast cells lacking VPS35 experienced aggravated toxicity. This toxicity can only be abated by the introduction of WT VPS35 rather than the PD-linked p.D620N mutant VPS35. However, the loss of TIF4631 and VPS35 genes in yeast models did not induce any lethality. This finding indicates that the deregulation of eIFG41 function under stressed conditions, such as proteotoxic stress induced by VPS35 deletion, can be deleterious. It is also demonstrated that PINK1 may interact with eIF4G1 and eIF4A in the initiation complex in an RNA-dependent manner (Fig. 3) [89]. The PD-linked G309D mutation in PINK1 hindered the interactions between PINK1 and eIF4G1. The inhibition of eIF4G1 in PINK1 mutant flies aggravated the neuromuscular degenerative phenotype [89]. Overexpression of eIF4G1 or calpastatin (an inhibitor of protease calpain, which cleaves eIF4G1) can lead to elevated levels of protein synthesis and improved viability in hippocampal CA1 neurons [88]. Although the pathological association of eIF4G1 as a PD gene with DA neuron degeneration in PD is still controversial, its significant roles in protein translation and its mutual crosstalk with other PD genes make it a potential molecular target in the proteostasis pathway for future studies in PD.

\section{Eukaryotic initiation factor $4 E$ (elF4E) and elF4E-binding protein 1 (4E-BP1) pathway in PD}

eIF4E is the initiation factor for determining whether the cap-dependent or IRES-mediated cap-independent protein translation will be initiated [90]. eIF4E directly binds to the cap structure of mRNA to facilitate the formation of the eIF4F complex on the mRNA cap structure, leading to the initiation of cap-dependent protein translation (Fig. 3) [91]. The integrity of protein structure and function of eIF4E determines the rate of global protein translation [92]. As a result, the tight control of the level and function of eIF4E is a necessity for the exquisite modulation of protein translation and proteostasis maintenance [92]. Regulation of the function of eIF4E can be a complicated model of modulation by kinase phosphorylation and its binding partners [68, 92]. eIF4E can be directly phosphorylated at S209 by eIF4E kinases, such as MAPK-activated protein kinase 1 (Mnk1), to enable its interaction with other initiation factors to form a stable eIF4F complex and enhance translation initiation [93]. eIF4E availability to protein translation initiation can also be modulated by its binding partners, mainly 4E-BP1 and eIF4G1 [94]. When cells are in a state conducive for global protein translation, eIF4G1 can bind to the dorsal surface of eIF4E via a recognition motif opposite to the cap binding pocket, promoting the interaction of eIF4E with the mRNA template and the initiation of translation [95]. eIF4G1 can also function as a scaffold to provide a docking site for Mnk1 to mediate the phosphorylation of eIF4E to enhance its function [96]. However, the paralog of eIF4G1, eIF4G2 (also known as P97), can interact with and sequester Mnk1 away from eIF4E, thereby inhibiting Mnk1-induced eIF4E phosphorylation and protein translation [96]. The influence of eIF4E function by $4 \mathrm{E}-\mathrm{BP} 1$ is also vital to the modulation of protein translation [97]. The binding of 4E-BP1 with eIF4E will sequester eIF4E away from the assembly of the eIF4F initiation complex, thus blocking protein translation [95, 98]. The 4E-BP1induced modulation of the protein translation can be affected by levels of 4E-BP1 and eIF4E in cells [97]. When the levels of intracellular eIF4E exceed the levels of 4E-BP1 in a dynamic cellular environment, the inhibition of protein translation by $4 \mathrm{E}-\mathrm{BP} 1$ becomes ineffective [71]. Furthermore, kinase-induced 4E-BP1 phosphorylation can abrogate its binding with eIF4E, leading to the facilitation of protein translation [99]. 4E-BP1 can be phosphorylated and modulated by the mTOR signaling pathway and LRRK2 kinases [100]. Hyper-phosphorylated 4E-BP1 will be dissociated from eIF4E, leading to enhanced cap-dependent protein translation [71]. However, in the absence of growth factors and/or cellular stress, 4E-BP1 remains unphosphorylated, allowing it to competitively sequester the eIF4E, thereby inhibiting the translation initiation mechanism [101].

Disturbance of the eIF4E and 4E-BP1 pathway can be disease related. 4E-BP1's function is understood to be neuroprotective, whereas elevated levels of eIF4E inducing translation facilitation can be pathological. It was found that the deregulated translation induced by either the upregulation of eIF4E or knock-out of 4E-BP1 is relevant to the onset of autism spectrum disorder in mice [102]. The upregulated expression of eIF4E can contribute to tumor formation [103]. Recent studies have implicated the relevance of the eIF4E and 4E-BP1 pathway in PD pathogenesis [32]. The levels of eIF4E can be modulated via ubiquitin-mediated proteasomal degradation [104]. Parkin, a PD-related E3 ubiquitin ligase, was found to interact with eIF4E and colocalize in developing oocytes [105]. In Drosophila ovarian models with the Parkin P23 mutant, the level of eIF4E is elevated [105]. Furthermore, suppression of eIF4E can rescue the observed fertility and developmental defects in the viability and size in Parkin P23 mutant Drosophila pupae [105]. Therefore, Parkin may function as the E3 ubiquitin ligase to promote the degradation of eIF4E by UPS. The Parkin mutation-induced impairment of Parkin E3 ligase activity may lead to the upregulation of eIF4E levels, which can be deleterious to proteostasis maintenance and DA neuron cell viability under stress. Furthermore, the eIF4E and 4E-BP1 pathway can be 
modulated by LRRK2 kinases [106]. LRRK2 is found to directly phosphorylate 4E-BP1 at the site Threonine (T) $37 / \mathrm{T} 46$ both in vivo and in vitro, leading to subsequent hyperphosphorylation of 4E-BP1 at T70 and S65 by LRRK2 or other protein kinases [106]. The phosphorylation of $4 \mathrm{E}-\mathrm{BP} 1$ by the LRRK2 kinase promotes the dissociation of eIF4E from 4E-BP1, leading to enhanced eIF4E functions, accelerated protein translation and disturbed proteostasis under stress [106]. The PD-linked mutant LRRK2, such as G2019S LRRK2 mutant with increased LRRK2 kinase activity, can induce hyperphosphorylation of 4E-BP1 and deregulated protein translation, which can be relevant to LRRK2 mutationinduced DA neuron degeneration in PD [106]. The neuroprotective roles of $4 \mathrm{E}-\mathrm{BP} 1$ can be evidenced in multiple PD models. The overexpression of 4E-BP1 was suggested to alleviate the Drosophila PINK1 mutant phenotype via upregulation of the cap-independent translation of various stress-related genes, including anti-oxidant genes [107]. The loss of Drosophila LRRK2induced hypo-phosphorylation of 4E-BP1 can contribute to the protection of DA neurons and the alleviation of PD-like symptoms in Parkin/PINK1 mutant fly PD models [107]. The overexpression of Thor, the Drosophila ortholog of mammalian 4E-BP1, in Parkin loss-offunction or PINK1 mutant Drosophila can suppress DA neuron degeneration and alleviate the PD-like phenotype in these flies [107]. Furthermore, the overexpression of 4E-BP1 can also rescue PD phenotypes in $\mathrm{CHCHD} 2$ loss-of-function Drosophila PD model [108]. Thus far, accumulated evidence implicates the important functional balance of eIF4E and 4E-BP1 in the modulation of protein translation, which is vital to proteostasis maintenance and neuron survival under stress. Therefore, drugs or strategies targeting the eIF4E and 4E-BP1 pathway may have therapeutic significance to protect against neuron degeneration in PD and other neurodegenerative diseases.

\section{Ribosomal protein S15 (RPS15) as a molecular target in PD} The human ribosomal protein RPS15 is a component of the $40 \mathrm{~S}$ ribosome subunit and plays a central role in ribosome biogenesis and protein translation [109]. RPS15 is shown to stimulate both cap-dependent and cap-independent protein translation [110]. It was reported that RPS15 can function to promote the export of pre-40S particles from the nucleus to the cytosol [111]. Mutations in RPS15 were found to be attributed to $10-20 \%$ of aggressive chronic lymphocytic leukemia [112]. The upregulated level of RPS15 was found to be connected to nasopharyngeal carcinoma with significant roles of RPS15 in the modulation of protein translation [113]. Recent findings have demonstrated that RPS15 can be the substrate of LRRK2 kinases, which is implicated in LRRK2 mutation-induced DA neuron degeneration in PD [114]. LRRK2 was demonstrated to phosphorylate RPS15 at T136 [114]. It was found that the pathogenic G2019S and I2020T mutant LRRK2 proteins promoted the phosphorylation of RPS15, contributing to the uncontrolled protein synthesis and subsequent DA neurotoxicity [114]. Thus, LRRK2 kinases may modulate protein translation via phosphorylation of both RPS15 and EF-4B1. The enhanced phosphorylation of RPS15 and EF-4B1 by LRRK2 mutants can promote global protein translation [110, 114]. Previous studies have demonstrated that endogenous DA can be a deleterious factor in DA neurons, as DA can be oxidized to generate toxic byproducts, inclusive of reactive oxygen species (ROS) and highly reactive DA quinones (DAQ) [115]. The toxic byproducts derived from DA oxidation can actively modify the function of proteins, leading to inactivation of proteins and protein misfolding and aggregation [115]. Therefore, the enhanced protein translation induced by PD-linked LRRK2 mutations in DA neurons may facilitate the accumulation of DA modified and misfolded proteins, which can be adverse to proteostasis maintenance and DA neuron viability. However, it was found that PD-linked R1441C and R1441G LRRK2 mutants cannot influence the phosphorylation stage of RPS15 [114]. Phospho-deficient RPS15 cannot rescue R1441C LRRK2 mutant-induced DA neurotoxicity [114]. Therefore, more work is needed to investigate the PD-linked LRRK2 mutation-induced deregulation of protein translation and disturbance of proteostasis significant to $\mathrm{PD}$ pathogenesis and therapy.

\section{Molecular targets in the mammalian target of rapamycin (mTOR) pathway}

Recent findings have implicated the mTOR pathway and its deregulation in PD pathogenesis [114]. mTOR is an evolutionary conserved, ubiquitous $\mathrm{S} / \mathrm{T}$ protein kinase belonging to a subgroup of kinases called phosphoinositide 3-kinase-related kinases (PIKKs) [116]. The physiological function of the mTOR pathway is critical to synaptic plasticity, learning and cortical development as well as neuronal survival $[117,118]$. The mTOR protein interacts with other proteins and serves as the core component of two distinct protein complexes: mTORC1 (the Rapamycin-sensitive mTOR complex 1) and mTORC2 (the Rapamycin-insensitive mTOR complex 2) [119].

mTORC1 is composed of the mTOR protein, the regulatory-associated protein of mTOR (Raptor), the mammalian lethal with SEC13 protein 8 (mLST8) and the noncore components PRAS40 and DEPTOR proteins [120]. mTORC1 kinase can function to modulate protein translation via phosphorylation of its two downstream substrates, ribosomal protein S6 kinase beta-1 (S6K1) and 4E-BP1 in a dynamic cellular environment. Hyperactive mTORC1 signaling can lead to the 
phosphorylation of 4E-BP1 and the release of eIF4E for enhancement of cap-dependent protein translation. Activated mTORC1 can also phosphorylate and activate S6K1 at T389 to further facilitate translation initiation and elongation via S6K1-induced subsequent phosphorylation of the ribosomal protein S6 (RPS6), eIF4B and elongation factor eEF2K, respectively [25]. On the other hand, mTORC1 kinase can inhibit autophagy via phosphorylation of the Unc51-like kinase 1 (ULK1) to inhibit the formation of a macrocomplex (ULK1 / Atg13 / FIP20) which is vital for autophagosome formation and autophagy initiation [121]. The inhibition of autophagy by activated mTORC1 kinase will inhibit the clearance of misfolded protein, which further aggravates protein aggregation, proteostasis disturbance and DA neuron viability impairment [122]. Thus far, findings have indicated that the hyperactive mTORC1 pathway is implicated in DA neurodegeneration, whereas modulation of the mTORC1 pathway can be significant to therapy against DA neurodegeneration in PD [123]. Selective mTORC1 inhibitors, Rapamycin and its analogues, have demonstrated some neuroprotective capacity in various PD models [124, 125]. Rapamycin was found to mitigate the side effect of the anti-PD drug L-Dopa, such as dyskinesia, in a PD mouse model [124]. Moreover, Temisrolimus, a Rapamycin analogue, is found to ameliorate the behavioral deficits in an MPTP mouse PD model [126]. Other mTORC1 inhibitors, such as metformin, minocycline and celastrol, are found to regulate protein translation via modulation of the mTORC1 kinase activity and contribute to improved proteostasis maintenance and DA neuron survival [127-129].

mTORC1 signaling was also implicated in genetic factor-induced DA neurodegeneration in PD. The mTORC1 kinase-induced activation of S6K aggravates the fly PD phenotype in a mutant PINK1 fly model, which can be rescued by WT Parkin [130]. However, down-regulation of protein translation by the knockdown of S6K, RPS6 or ribosomal protein 9 (RPS9) can rescue PINK1 mutant fly phenotypes, supporting the pathological link of the mTORC1 pathway with neurodegeneration in FPD [130]. In a study wherein hypoxia was induced, the loss of PINK1 was found to disrupt the dephosphorylation of 4E-BP1, leading to facilitated protein translation [131]. These findings have indicated the potential functional crosstalk between the mTORC1 and PINK1-Parkin pathways with relevance to protein translation modulation and DA neuron degeneration in PD [130]. LRRK2 was also shown to have crosstalk with the mTOR pathways via phosphorylation of 4E-BP1 and Akt [132]. A recent pilot screening-based preclinical study has identified new pharmacological agents with mTORC1 kinase inhibition capability to modulate protein translation and protect DA neurons in a DJ-1 $\beta$ mutant PD fly model [133]. New potent and capable neuroprotective mTORC1 inhibitors may be developed in the near future to treat progressive DA neuron degeneration in SPD as well as in FPD.

mTORC2 is composed of the mTOR protein, the Rapamycin-insensitive companion of mTOR (RICTOR), MLST8, and mammalian stress-activated protein kinase interacting protein 1 (mSIN1) [134]. mTORC2 play roles in the modulation of cell metabolism, motility, survival and proliferation [122]. Inhibition of $\mathrm{mTORC} 2$ will impair cell proliferation, which is implicated in cancer therapy $[135,136]$. Akt is a downstream target of mTORC2 and is vital to cell viability and proliferation [122]. Multiple studies demonstrate that Akt/Akt1 can be a substrate of LRRK2 kinase and that the kinase activity of Akt can be abrogated by PD-associated LRRK2 mutations [137]. Therefore, the impairment of proliferative mTORC2-Akt pathway signaling by PD-linked LRRK2 mutants may also contribute to LRRK2 mutation-induced DA neuron degeneration in PD.

\section{Conclusions}

The maintenance of cell proteostasis is vital to many physiological events, and disturbance of proteostasis can be pathologically significant for neurodegeneration in PD and other neurodegenerative disorders. This can be indicative through the formation of featured protein aggregates in affected patient brains with PD and other neurodegenerative diseases. Proteostasis can be maintained by modulation of protein translation, enhancement of chaperone capacity and protein clearance via UPS and autophagy. The modulation of protein translation to maintain proteostasis is the primary mechanism for cells to cope with stress-induced challenges. Previous findings have shown that the facilitated protein translation can be either adverse or advantageous to neuron survival under different scenarios [138, 139]. Similarly, inhibition of protein translation has been identified to be either protective or detrimental to cells [67]. The accumulation of misfolded proteins in the ER will activate erUPR and enhance phosphorylation of eIF2 $\alpha$ protein [140]. The phosphorylated eIF2 $\alpha$ can suppress global protein translation, which can help cells cope with protein misfolding-induced cell degeneration [140]. However, severe or prolonged erUPR can be deleterious to cells [141]. Prolonged inhibition of global protein translation can lead to apoptosis, which is a promising therapeutic strategy for cancer therapy [67]. However, the inhibition of protein translation is suggested to be neuroprotective in PD models [32]. The translation inhibition by acute exposure to cycloheximide is identified to inhibit hypertonicity-induced aggregation of polyglutamine and endogenous $\alpha$-syn in C elegans [142]. Thus far, several FDA-approved drugs (GBZ, Trazodone and 
DBM) targeting eIF2 $\alpha$ phosphorylation for inducing the arrest or facilitation of protein translation are shown to be neuroprotective against DA neuron degeneration in different PD models [32, 143]. GBZ can inhibit GADD34 to enhance eIF $2 \alpha$ phosphorylation, contributing to the arrest of protein translation [144]. However, Trazodone and DBM can abrogate eIF2 $\alpha$ phosphorylation-induced translation arrest and facilitate protein translation [51]. They have opposing impacts on eIF $2 \alpha$ phosphorylation and protein translation, but all of these drugs are identified to have neuroprotective effects.

Similar situations can be identified in eIF4G1 and eIF4E-4E-BPs pathways. The mutant LRRK2 enhances the phosphorylation of 4E-BP1 to facilitate eIF4E-induced translation initiation and protein synthesis, which is suggested to be implicated in LRRK2 mutation-induced DA neuron degeneration in PD $[106,110]$. The LRRK2 mutations can also phosphorylate the ribosomal RPS15 protein to facilitate protein translation [114]. These findings indicate that the accelerated protein biogenesis induced by LRRK2 mutations can be relevant to LRRK2 mutation-induced DA neuron degeneration. Other researchers have reported that the increased levels of $4 \mathrm{E}-\mathrm{BP} 1$ to interact with and sequester eIF4E can be protective of DA neurons, suggesting that the deceleration of protein translation can promote cell survival and be neuroprotective [107, 145]. However, PD-linked eIF4G1 A502V and R1205H variants are found to disturb the protein translation initiation with the potential inhibition of protein translation, which is supposed to be relevant to eIF4G1 mutation-induced DA neuron degeneration in PD [75].

The dual influences of the opposing modulations of protein translation on cell viability can also be visualized in the mTORC1 signaling pathway. Inhibition of the mTORC1 pathway by Rapamycin has been demonstrated to be neuroprotective. However, overexpression of the WT mTOR protein or the constitutively active S6K1 to facilitate protein translation is found to protect against PD toxin-induced in vitro dopaminergic PC12 cell death [145]. mTORC1 can phosphorylate and inhibit ULK1 to suppress autophagy, which can be adverse to cell viability. However, it has recently been reported that ULK1 expression is upregulated to protect against $\mathrm{MPP}^{+}$-induced MN9D cell vulnerability via inhibition of mTOR kinase-induced T389 phosphorylation and activation of S6k1 [146]. Thus, ULK1 and mTOR kinase seem to form a complicated feedback loop with reciprocal modulation of their activities and functions.

Thus far, multiple molecular targets in pathways for modulating protein translation vital to proteostasis and cell viability have been identified. However, the facilitation or inhibition of protein translation can have complicated impacts on proteostasis and neuron survival [147].
Multiple and complicated factors may account for some inconsistent findings. Different in vitro and in vivo experimental models utilized and challenges with different stressors for different time periods and with different magnitudes may lead to distinct conclusions. For example, at a downstream erUPR stage, prolonged activation of erUPR can be lethal; therefore, the application of drugs to inhibit eIF2 $\alpha$ phosphorylation and promote protein translation at a downstream erUPR stage can alleviate the erUPR-induced neurodegeneration. This mechanism may account for the GBZ-induced neuroprotection in some PD models. However, the administration of drugs inhibiting eIF2 $\alpha$ phosphorylation at an earlier stage of erUPR may aggravate protein misfolding and aggregation, which can be deleterious to DA neuron survival. Such a mechanism may account for Trazodoneinduced onset of PD symptoms in some patients. Currently, little is known about molecular targets and detailed molecular events in the modulation of protein translation and the subsequent impact on proteostasis and cell survival. More future works are warranted to improve our understanding of PD pathogenesis and contribute to the development of novel effective anti-PD drugs or therapies.

\section{Abbreviations}

4E-BP1: elF4E-binding protein 1; 5'UTR: 5' untranslated region; AD: Alzheimer's disease; ALS: Amyotrophic lateral sclerosis; CITE: Capindependent translation element; DA: Dopamine; DAQ: Dopamine quinone; DBM: Dibenzoylmethane; eEF2: eukaryotic elongation factor 2;

elF2: eukaryotic initiation factor 2; elF4E: eukaryotic initiation factor $4 \mathrm{E}_{\text {; }}$ elF4F: eukaryotic initiation factor 4F; elFs: eukaryotic initiation factors; ER: Endoplasmic reticulum; ERAD: ER-associated degradation; erUPR: ER unfolded protein response; FPD: Familial form of PD; GBZ: Guanabenz; GEF: Guanine nucleotide exchange factor; GWAS: Genome-wide analysis study; IRES: Internal ribosomal entry site; ISRIB: An integrated stress response inhibitor; LBs: Lewy bodies; Met-tRNA ${ }_{i}^{\text {Met: }}$ Initiator methionyl-tRNA;

mLST8: mammalian lethal with SEC13 protein 8; mSIN1: mammalian stressactivated protein kinase interacting protein 1; mTOR: mammalian target of Rapamycin; mTORC1: Rapamycin-sensitive mTOR complex 1;

mTORC2: Rapamycin-insensitive mTOR complex 2; PABP: Poly-A binding protein; PBMCs: Peripheral blood mononuclear cells; PD: Parkinson's disease; PFAR: Protein folding activity of the ribosome; PIC: Preinitiation complex; PIKKs: Phosphoinositide 3-kinase-related kinases; PP1: Protein phosphatase 1; Raptor: Regulatory-associated protein of mTOR; RFs: Translation release factors; RICTOR: Rapamycin-insensitive companion of mTOR; ROS: Reactive oxygen species; RPS15: Ribosomal protein S15; RPS6: Ribosomal protein S6; S6K1: Ribosomal protein S6 kinase beta-1; SN: Substantia Nigra pars compacta; SPD: Sporadic form of Parkinson's disease; TIF4631: yeast homolog of elF4G1; ULK1: Unc51-like kinase 1; UPS: Ubiquitin-proteasome system; WT: Wild type; $a-$ syn: $a-$-synuclein

\section{Acknowledgments}

We thank the Singapore National Medical Research Council (STaR and the clinical translational research program in Parkinson's disease) for their support.

\section{Funding}

The Singapore National Medical Research Council (NMRC) grants including STaR and a clinical translational research program in Parkinson's disease.

Availability of data and materials

All data generated or analyzed during this study are included in this published article. 


\section{Authors' contributions}

ZZD, TS and LJCT reviewed the literature and drafted the manuscript. TEK and CYX critically revised and touched up the manuscript. All authors read and approved the final manuscript.

\section{Ethics approval and consent to participate}

Not applicable.

\section{Consent for publication}

Not applicable.

\section{Competing interests}

The authors declare that they have no competing interests.

\section{Author details}

'Department of Research, National Neuroscience Institute, 11 Jalan Tan Tock Seng, Singapore 308433, Singapore. ${ }^{2}$ Department of Neurology, Singapore General Hospital, Outram Road, Singapore 169608, Singapore. ${ }^{3}$ Signature Research Program in Neuroscience and Behavioural Disorders, Duke-NUS Medical School Singapore, 8 College Road, Singapore, Singapore.

\section{Received: 24 August 2018 Accepted: 14 January 2019}

\section{Published online: 04 February 2019}

\section{References}

1. Meara RJ. Review: The Pathophysiology of the Motor Signs in Parkinson's Disease. Age Ageing. 1994;23:342-6.

2. Tan LCS. Epidemiology of Parkinson's disease. Neurol Asia. 2013;18:231-8.

3. Van Laar VS, Berman SB. Mitochondrial dynamics in Parkinson's disease. Exp Neurol. 2009;218:247-56. https://doi.org/10.1016/j.expneurol.2009.03.019.

4. Bravo-San Pedro JM, Gómez-Sánchez R, Pizarro-Estrella E, Niso-Santano M, González-Polo RA, Fuentes Rodríguez JM. Parkinsons disease: leucine-rich repeat kinase 2 and autophagy, intimate enemies. Parkinsons Dis. 2012;2012: 151039.

5. Polymeropoulos MH, Lavedan C, Leroy E, Ide SE, Dehejia A, Dutra A, et al. Mutation in the a-Synuclein Gene Identified in Families with Parkinson\&\#039:s Disease. Science. 1997:276:2045-7. http://science. sciencemag.org/content/276/5321/2045.

6. Lim KL, Lim TM. Molecular mechanisms of neurodegeneration in Parkinson's disease: clues from Mendelian syndromes. IUBMB Life. 2003;55:315-22.

7. Valente EM, Salvi S, lalongo T, Marongiu R, Elia AE, Caputo V, et al. PINK mutations are associated with sporadic early-onset parkinsonism. Ann Neurol. 2004;56:336-41.

8. Bonifati V, Rizzu P, van Baren MJ, Schaap O, Breedveld GJ, Krieger E, et al. Mutations in the DJ-1 Gene Associated with Autosomal Recessive EarlyOnset Parkinsonism. Science. 2003;299:256-9. http://science.sciencemag.org/ content/299/5604/256.

9. Di Fonzo A, Dekker MCJ, Montagna P, Baruzzi A, Yonova EH, Guedes LC, et al. FBXO7 mutations cause autosomal recessive, early-onset parkinsonianpyramidal syndrome. Neurology. 2009;72:240-5. http://n.neurology.org/ content/72/3/240

10. Funayama M, Ohe K, Amo T, Furuya N, Yamaguchi J, Saiki S, et al. CHCHD2 mutations in autosomal dominant late-onset Parkinson's disease: a genomewide linkage and sequencing study. Lancet Neurol. 2015;14:274-82. https:// doi.org/10.1016/S1474-4422(14)70266-2.

11. Di Fonzo A, Rohé CF, Ferreira J, Chien HF, Vacca L, Stocchi F, et al. A frequent LRRK2 gene mutation associated with autosomal dominant Parkinson's disease. Lancet. 2005;365:412-5.

12. Gibb WRG, Lees AJ. Occasional review the relevance of the Lewy body to the pathogenesis of idiopathic Parkinson's disease. J Neurol Neurosurg Psychiatry. 1988;51:745-52.

13. Park Y, Hoang QQ. Combating Parkinson's disease-associated toxicity by modulating proteostasis. Proc Natl Acad Sci. 2017;114:803-4. https://doi.org/ 10.1073/pnas.1620082114

14. Balch WE, Morimoto RI. Adapting Proteostatis for Disease Intervention. Science. 2008:319:916-9.

15. Klaips CL, Jayaraj GG, Hartl FU. Pathways of cellular proteostasis in aging and disease. J Cell Biol. 2018;217:51-63.

16. Dahlberg AE, Brimacombe R, Atmadja J, Stiege W, Schuler D, Crick FHC, et al. The functional role of ribosomal RNA in protein synthesis. Cell. 1989; 57:525-9. https://doi.org/10.1016/0092-8674(89)90122-0.
17. Watkins SJ, Norbury CJ. Translation initiation and its deregulation during tumorigenesis. Br J Cancer. 2002:86:1023-7.

18. DeGracia DJ, Kumar R, Owen CR, Krause GS, White BC. Molecular pathways of protein synthesis inhibition during brain reperfusion: implications for neuronal survival or death. J Cereb Blood Flow Metab. 2002;22:127-41.

19. Merrick WC. Cap-dependent and cap-independent translation in eukaryotic systems. Gene. 2004;332:1-11.

20. Sokabe M, Fraser CS. Human eukaryotic initiation factor 2 (elF2)-GTP-mettRNAi ternary complex and elF3 stabilize the $43 \mathrm{~S}$ preinitiation complex. J Biol Chem. 2014;289:31827-36.

21. Hashem Y, Des Georges A, Dhote V, Langlois R, Liao HY, Grassucci RA, et al. Structure of the mammalian ribosomal 435 preinitiation complex bound to the scanning factor DHX29. Cell. 2013;153:1108-19. https://doi.org/10.1016/j. cell.2013.04.036.

22. Jurado AR, Tan D, Jiao X, Kiledjian M, Tong L. Structure and function of premRNA $5^{\prime}$-end capping quality control and $3^{\prime}$-end processing. Biochemistry. 2014:53:1882-98.

23. Brina D, Grosso S, Miluzio A, Biffo S. Translational control by 805 formation and 605 availability: the central role of elF6, a rate limiting factor in cell cycle progression and tumorigenesis. Cell Cycle. 2011;10:3441-6.

24. Komar AA, Hatzoglou M. Exploring Internal Ribosome Entry Sites as Therapeutic Targets. Front Oncol. 2015;5:1-10. https://doi.org/10.3389/fonc. 2015.00233

25. Kaul G, Pattan G, Rafeequi T. Eukaryotic elongation factor-2 (eEF2): its regulation and peptide chain elongation. Cell Biochem Funct. 2011;29:227-34.

26. Beringer $M$, Bruell $C$, Xiong $L$, Pfister $P$, Bieling $P$, Katunin VI, et al. Essential mechanisms in the catalysis of peptide bond formation on the ribosome. Biol Chem. 2005:280:36065-72

27. Frank J, Gao H, Sengupta J, Gao N, Taylor DJ. The process of mRNA-tRNA translocation. Proc Natl Acad Sci. 2007:104:19671-8. https://doi.org/10.1073/ pnas.0708517104.

28. Joseph S. After the ribosome structure: how does translocation work? RNA 2003;9:160-4. https://doi.org/10.1261/rna.2163103.

29. Jackson RJ, Hellen CUT, Pestova TV. The mechanism of eukaryotic translation initiation and principles of its regulation. Nat Rev Mol Cell Biol. 2010:11:113-27. https://doi.org/10.1038/nrm2838.

30. Stolboushkina EA, Garber MB. Eukaryotic type translation initiation factor 2: structure-functional aspects. Biochemistry (Mosc). 2011;76:283-94.

31. Fernandez J, Yaman I, Sarnow P, Snider MD, Hatzoglou M. Regulation of internal ribosomal entry site-mediated translation by phosphorylation of the translation initiation factor elF2a. J Biol Chem. 2002;277:19198-205.

32. Kim JW, Abalde-Atristain L, Jia H, Martin I, Dawson TM, Dawson VL. Chapter 9 - protein translation in Parkinson's disease. San Diego: Academic Press; 2017. p. 281-309. https://doi.org/10.1016/B978-0-12-803783-6.00009-2.

33. Holcik M. Could the elF2a-Independent Translation Be the Achilles Heel of Cancer? Front Oncol. 2015;5:1-8. https://doi.org/10.3389/fonc.2015.00264.

34. Blais JJD, Filipenko V, Bi M, Harding HHP, Ron D, Koumenis C, et al. Activating transcription factor 4 is translationally regulated by hypoxic stress. Mol Cell Biol. 2004:24:7469-82. https://doi.org/10.1128/MCB.24.17.7469.

35. Oyadomari S, Harding HP, Zhang Y, Oyadomari M, Ron D. Dephosphorylation of translation initiation factor $2 a$ enhances glucose tolerance and attenuates Hepatosteatosis in mice. Cell Metab. 2008;7:520-32.

36. Gerlitz G, Jagus R, Elroy-Stein O. Phosphorylation of initiation factor-2a is required for activation of internal translation initiation during cell differentiation. Eur J Biochem. 2002:269:2810-9.

37. Rojas M, Vasconcelos G, Dever TE. An elF2a-binding motif in protein phosphatase 1 subunit GADD34 and its viral orthologs is required to promote dephosphorylation of elF2a. Proc Natl Acad Sci. 2015;112:E346675. https://doi.org/10.1073/pnas.1501557112

38. Trinh MA, Klann E. Translational control by elF2a kinases in long-lasting synaptic plasticity and long-term memory. Neurobiol Learn Mem. 2013;105: 93-9. https://doi.org/10.1016/j.nlm.2013.04.013.

39. Moreno JA, Radford H, Peretti D, Steinert JR, Verity N, Martin MG, et al. Sustained translational repression by elF2a-P mediates prion neurodegeneration. Nature. 2012:485:507-11. https:/doi.org/10.1038/nature11058.

40. Bellucci A, Navarria L, Zaltieri M, Falarti E, Bodei S, Sigala S, et al. Induction of the unfolded protein response by a-synuclein in experimental models of Parkinson's disease. J Neurochem. 2011:116:588-605.

41. Jiang $P$, Gan M, Ebrahim AS, Lin WL, Melrose HL, Yen SHC. ER stress response plays an important role in aggregation of -synuclein. Mol Neurodegener. 2010;5:1-16. 
42. Liu M, Qin L, Wang L, Tan J, Zhang H, Tang J, et al. a-synuclein induces apoptosis of astrocytes by causing dysfunction of the endoplasmic reticulum-Golgi compartment. Mol Med Rep. 2018;18:322-32.

43. Abisambra JF, Jinwal UK, Blair LJ, O'Leary JC, Li Q, Brady S, et al. Tau accumulation activates the unfolded protein response by impairing endoplasmic reticulum-associated degradation. J Neurosci. 2013;33:9498-507. https://doi.org/10.1523/JNEUROSCI.5397-12.2013.

44. Hoozemans JJM, van Haastert ES, Eikelenboom P, de Vos RAl, Rozemuller JM, Scheper W. Activation of the unfolded protein response in Parkinson's disease. Biochem Biophys Res Commun. 2007;354:707-11.

45. Mutez E, Nkiliza A, Belarbi K, de Broucker A, Vanbesien-Mailliot C, Bleuse S, et al. Involvement of the immune system, endocytosis and EIF2 signaling in both genetically determined and sporadic forms of Parkinson's disease. Neurobiol Dis. 2014;63:165-70.

46. Celardo I, Costa AC, Lehmann S, Jones C, Wood N, Mencacci NE, et al. Mitofusin-mediated ER stress triggers neurodegeneration in pink1/parkin models of Parkinson's disease. Cell Death Dis. 2016;7:e2271. https://doi.org/ 10.1038/cddis.2016.173

47. Mercado G, Castillo V, Soto P, López N, Axten JM, Sardi SP, et al. Targeting PERK signaling with the small molecule GSK2606414 prevents neurodegeneration in a model of Parkinson's disease. Neurobiol Dis. 2018; 112:136-48.

48. Sidrauski C, Tsai JC, Kampmann M, Hearn BR, Vedantham P, Jaishankar P, et al. Pharmacological dimerization and activation of the exchange factor elF2B antagonizes theintegrated stress response. Elife. 2015;2015:1-27.

49. Halliday M, Radford H, Sekine Y, Moreno J, Verity N, Le Quesne J, et al. Partial restoration of protein synthesis rates by the small molecule ISRIB prevents neurodegeneration without pancreatic toxicity. Cell Death Dis. 2015;6:e1672-9. https://doi.org/10.1038/cddis.2015.49.

50. Hughes D, Mallucci GR. The unfolded protein response in neurodegenerative disorders - therapeutic modulation of the PERK pathway. FEBS J. 2018:1-14. https://doi.org/10.1111/febs.14422.

51. Halliday M, Radford H, Zents KAM, Molloy C, Moreno JA, Verity NC, et al. Repurposed drugs targeting elF2a-P-mediated translational repression prevent neurodegeneration in mice. Brain. 2017;140:1768-83.

52. Takano K, Kitao Y, Tabata Y, Miura H, Sato K, Takuma K, et al. A dibenzoylmethane derivative protects dopaminergic neurons against both oxidative stress and endoplasmic reticulum stress. Am J Physiol Cell Physiol. 2007;293:1884-94.

53. Albanese A, Rossi P, Altavista MC. Can trazodone induce parkinsonism? Clin Neuropharmacol. 1988;11:180-2.

54. Mayor JS, Pacheco AP, Esperança S, Oliveira E, Silva A. Trazodone in the elderly: risk of extrapyramidal acute events. BMJ Case Rep. 2015;2015: bcr2015210726.

55. Tsaytler P, Harding HP, Ron D, Bertolotti A. Selective inhibition of a regulatory subunit of protein phosphatase 1 restores proteostasis. Science. 2011:332:91-4

56. Neuber C, Uebeler J, Schulze T, Sotoud H, El-Armouche A, Eschenhagen T. Guanabenz interferes with ER stress and exerts protective effects in cardiac myocytes. PLoS One. 2014;9:1-9.

57. Barbezier N, Chartier A, Bidet Y, Buttstedt A, Voisset C, Galons H, et al. Antiprion drugs 6-aminophenanthridine and guanabenz reduce PABPN1 toxicity and aggregation in oculopharyngeal muscular dystrophy. EMBO Mol Med. 2011;3:35-49.

58. Bella ED, Tramacere I, Antonini G, Borghero G, Capasso M, Caponnetto C, et al. Protein misfolding, amyotrophic lateral sclerosis and guanabenz: protocol for a phase II RCT with futility design (ProMISe trial). BMJ Open. 2017;7:1-9.

59. Zhu Y, Fotinos A, Mao LLJ, Atassi N, Zhou EW, Ahmad S, et al. Neuroprotective agents target molecular mechanisms of disease in ALS. Drug Discov Today. 2015;20:65-75. https://doi.org/10.1016/j.drudis.2014.08.016.

60. Sun X, Aimé P, Dai D, Ramalingam N, Crary JF, Burke RE, et al. Guanabenz promotes neuronal survival via enhancement of ATF4 and parkin expression in models of Parkinson disease. Exp Neurol. 2018;303:95-107. https://doi. org/10.1016/j.expneurol.2018.01.015

61. Das I, Krzyzosiak A, Schneider K, Wrabetz L, D'Antonio M, Barry N, et al Preventing proteostasis diseases by selective inhibition of a phosphatase regulatory subunit. Science. 2015;348:239-42.

62. Crespillo-Casado A, Chambers JE, Fischer PM, Marciniak SJ, Ron D. PPP1R15A-mediated dephosphorylation of elF2a is unaffected by sephin1 or guanabenz. Elife. 2017;6:1-29.
63. Takigawa S, Chen A, Nishimura A, Liu S, Li BY, Sudo A, et al. Guanabenz downregulates inflammatory responses via elF2a dependent and independent signaling. Int J Mol Sci. 2016;17:1-12.

64. Pang Y, Kurella S, Voisset C, Samanta D, Banerjee D, Schabe A, et al. The antiprion compound 6-aminophenanthridine inhibits the protein folding activity of the ribosome by direct competition. J Biol Chem. 2013;288:19081-9.

65. Banerjee D, Sanyal S. Protein folding activity of the ribosome (PFAR) - a target for antiprion compounds. Viruses. 2014;6:3907-24.

66. Buchberger A, Bukau B, Sommer T. Protein quality control in the cytosol and the endoplasmic reticulum: brothers in arms. Mol Cell. 2010;40:238-52. https://doi.org/10.1016/j.molcel.2010.10.001.

67. Lindqvist LM, Vikström I, Chambers JM, McArthur K, Ann Anderson M, Henley KJ, et al. Translation inhibitors induce cell death by multiple mechanisms and $\mathrm{Mcl}-1$ reduction is only a minor contributor. Cell Death Dis. 2012;3:1-9.

68. Caron S, Charon M, Cramer E, Sonenberg N, Dusanter-Fourt I. Selective modification of eukaryotic initiation factor $4 \mathrm{~F}$ (elF4F) at the onset of cell differentiation: recruitment of elF4GII and long-lasting phosphorylation of elF4E. Mol Cell Biol. 2004;24:4920-8.

69. Tarun SZ, Sachs AB. Association of the yeast poly (a) tail binding protein with translation initiation factor elF-4G. EMBO J. 1996;15:7168-77. https:// doi.org/10.1017/S0272263100014674.

70. Sonenberg N, Hinnebusch AG. Regulation of translation initiation in eukaryotes: mechanisms and biological targets. Cell. 2009;136:731-45. https://doi.org/10.1016/j.cell.2009.01.042.

71. Svitkin YV, Herdy B, Costa-Mattioli M, Gingras A-C, Raught B, Sonenberg N Eukaryotic translation initiation factor $4 \mathrm{E}$ availability controls the switch between cap-dependent and internal ribosomal entry site-mediated translation. Mol Cell Biol. 2005;25:10556-65.

72. Howard A, Rogers AN. Role of translation initiation factor $4 \mathrm{G}$ in lifespan regulation and age-related health. Ageing Res Rev. 2014;13:115-24. https:// doi.org/10.1016/j.arr.2013.12.008.

73. Contreras V, Richardson MA, Hao E, Keiper BD. Depletion of the capassociated isoform of translation factor elF4G induces germline apoptosis in C. Elegans. Cell Death Differ. 2008;15:1232-42.

74. Smith ED, Tsuchiya M, Fox LA, Dang N, Hu D, Kerr EO, et al. Quantitative evidence for conserved longevity pathways between divergent eukaryotic species. Genome Res. 2008;18:564-70.

75. Chartier-Harlin MC, Dachsel JC, Vilariño-Güell C, Lincoln SJ, Leprêtre F, Hulihan MM, et al. Translation initiator EIF4G1 mutations in familial parkinson disease. Am J Hum Genet. 2011;89:398-406.

76. Nuytemans K, Bademci G, Inchausti V, Dressen A, Kinnamon DD, Mehta A, et al. Whole exome sequencing of rare variants in EIF4G1 and VPS35 in Parkinson disease. Neurology. 2013;80:982-9. http://n.neurology.org/ content/80/11/982.

77. Huttenlocher J, Krüger R, Capetian P, Lohmann K, Brockmann K, Csoti I, et al EIF4G1 is neither a strong nor a common risk factor for Parkinson's disease: evidence from large European cohorts. J Med Genet. 2015;52:37-41.

78. Lesage S, Condroyer C, Klebe S, Lohmann E, Durif F, Damier P, et al. EIF4G1 in familial Parkinson's disease: Pathogenic mutations or rare benign variants? Neurobiol Aging. 2012;33:2233.e1-5. https://doi.org/10.1016/j. neurobiolaging.2012.05.006.

79. Schulte EC, Mollenhauer B, Zimprich A, Bereznai B, Lichtner $\mathrm{P}$, Haubenberger $D$, et al. Variants in eukaryotic translation initiation factor $4 \mathrm{G} 1$ in sporadic Parkinson's disease. Neurogenetics. 2012;13:281-5.

80. Tucci A, Charlesworth G, Sheerin UM, Plagnol V, Wood NW, Hardy J. Study of the genetic variability in a Parkinson's disease gene: EIF4G1. Neurosci Lett. 2012;518:19-22. https://doi.org/10.1016/j.neulet.2012.04.033.

81. Nichols N, Bras JM, Hernandez DG, Jansen IE, Lesage S, Lubbe S, et al. EIF4G1 mutations do not cause Parkinson's disease. Neurobiol Aging. 2015; 36:2444-2444.e4.

82. Chen YP, Chen $K$, Song W, Chen XP, Cao B, Huang R, et al. VPS35 Asp620Asn and EIF4G1 Arg1205His mutations are rare in Parkinson disease from Southwest China. Neurobiol Aging. 2013;34:1709.e7-8. https://doi.org/ 10.1016/j.neurobiolaging.2012.11.003.

83. Nishioka K, Funayama M, Vilariño-Güell C, Ogaki K, Li Y, Sasaki R, et al. EIF4G1 gene mutations are not a common cause of Parkinson's disease in the Japanese population. Park Relat Disord. 2014;20:659-61. https://doi.org/ 10.1016/j.parkreldis.2014.03.004.

84. Sudhaman S, Behari M, Govindappa ST, Muthane UB, Juyal RC, Thelma BK. VPS35 and EIF4G1 mutations are rare in Parkinson's disease among Indians. 
Neurobiol Aging. 2013;34:2442.e1-3. https://doi.org/10.1016/j. neurobiolaging.2013.04.025.

85. Blanckenberg J, Ntsapi C, Carr JA, Bardien S. EIF4G1 R1205H and VPS35 D620N mutations are rare in Parkinson's disease from South Africa. Neurobiol Aging. 2014;35:445.e1-3. https://doi.org/10.1016/j.neurobiolaging.2013.08.023.

86. Kalinderi K, Bostantjopoulou S, Katsarou Z, Dimikiotou M, Fidani L. D620N mutation in the VPS35 gene and R1205H mutation in the EIF4G1 gene are uncommon in the Greek population. Neurosci Lett. 2015;606:113-6. https:// doi.org/10.1016/j.neulet.2015.08.020

87. Dhungel N, Eleuteri S. Li L Bo, Kramer NJ, Chartron JW, Spencer B, et al. Parkinson's disease genes VPS35 and EIF4G1 interact genetically and converge on a-Synuclein. Neuron. 2015;85:76-88. https://doi.org/10.1016/j. neuron.2014.11.027.

88. Zimprich A, Benet-Pagès A, Struhal W, Graf E, Eck SH, Offman MN, et al. A mutation in VPS35, encoding a subunit of the retromer complex, causes late-onset parkinson disease. Am J Hum Genet. 2011;89:168-75.

89. Gehrke S, Wu Z, Klinkenberg M, Sun Y, Auburger G, Guo S, et al. PINK1 and parkin control localized translation of respiratory chain component mRNAs on mitochondria outer membrane. Cell Metab. 2015;21:95-108. https://doi. org/10.1016/j.cmet.2014.12.007.

90. Dyer JR, Michel S, Lee W, Castellucci VF, Wayne NL, Sossin WS. An activitydependent switch to cap-independent translation triggered by elF4E dephosphorylation. Nat Neurosci. 2003;6:219-20.

91. Richter JD, Sonenberg N. Regulation of cap-dependent translation by elF4E inhibitory proteins. Nature. 2005;433:477-80.

92. Shveygert M, Kaiser C, Bradrick SS, Gromeier M. Regulation of eukaryotic initiation factor $4 \mathrm{E}$ (elF4E) phosphorylation by mitogen-activated protein kinase occurs through modulation of Mnk1-elF4G interaction. Mol Cell Biol. 2010;30:5160-7. https://doi.org/10.1128/MCB.00448-10.

93. Whalen SG, Gingras AC, Amankwa L, Mader S, Branton PE, Aebersold R, et al. Phosphorylation of elF4E on Serine-209 by protein kinase $C$ is inhibited by the translational repressors, $4 \mathrm{E}-$ binding proteins. J Biol Chem. 1996;271:11831-7.

94. George A, Panda S, Kudmulwar D, Chhatbar SP, Nayak SC, Krishnan HH. Hepatitis C virus NS5A binds to the mRNA cap-binding eukaryotic translation initiation $4 \mathrm{~F}$ (elF4F) complex and up-regulates host translation initiation machinery through elF4E-binding protein 1 inactivation. J Biol Chem. 2012;287:5042-58.

95. Hershey PEC, Mcwhirter SM, Gross JD, Wagner G, Alber T, Sachs AB. NUCLEIC ACIDS, PROTEIN SYNTHESIS, AND MOLECULAR GENETICS: The cap-binding protein elF4E promotes folding of a functional domain of yeast translation initiation factor elF4G1. J Biol Chem. 1999:274:21297-304.

96. Pyronnet S, Imataka H, Gingras AC, Fukunaga R, Hunter T, Sonenberg N. Human eukaryotic translation initiation factor $4 \mathrm{G}$ (elF4G) recruits Mnk1 to phosphorylate elF4E. EMBO J. 1999;18:270-9.

97. Musa J, Orth MF, Dallmayer M, Baldauf M, Pardo C, Rotblat B, et al. Eukaryotic initiation factor 4E-binding protein 1 (4E-BP1): a master regulator of mRNA translation involved in tumorigenesis. Oncogene. 2016;35:4675-88. https://doi.org/10.1038/onc.2015.515.

98. Tee AR, Proud CG. Caspase cleavage of initiation factor $4 \mathrm{E}-$-binding protein 1 yields a dominant inhibitor of cap-dependent translation and reveals a novel regulatory motif. Mol Cell Biol. 2002;22:1674-83.

99. Brown CJ, Lim JJ, Leonard T, Lim HCA, Chia CSB, Verma CS, et al. Stabilizing the elF4G1 a-helix increases its binding affinity with elF4E: implications for peptidomimetic design strategies. J Mol Biol. 2011;405:736-53. https://doi. org/10.1016/j.jmb.2010.10.045.

100. Zhang $Y$, Zheng XFS. MTOR-independent 4E-BP1 phosphorylation is associated with cancer resistance to mTOR kinase inhibitors. Cell Cycle. 2012;11:594-603.

101. Marcotrigiano J, Gingras AC, Sonenberg N, Burley SK. Cap-dependent translation initiation in eukaryotes is regulated by a molecular mimic of elF4G. Mol Cell. 1999:3:707-16.

102. Gkogkas CG, Khoutorsky A, Ran I, Rampakakis E, Nevarko T, Weatherill DB, et al. Autism-related deficits via dysregulated elF4E-dependent translational control. Nature. 2013;493:371-7. https://doi.org/10.1038/nature11628.

103. Truitt ML, Conn CS, Shi Z, Seo Y, Barna M, Truitt ML, et al. Differential requirements for elF4E dose in Normal development and Cancer article differential requirements for elF4E dose in Normal development and Cancer. Cell. 2015;162:59-71. https://doi.org/10.1016/j.cell.2015.05.049.

104. Murata T, Shimotohno K. Ubiquitination and proteasome-dependent degradation of human eukaryotic translation initiation factor 4E. J Biol Chem. 2006;281:20788-800.
105. Ottone C, Galasso A, Gemei M, Pisa V, Gigliotti S, Piccioni F, et al. Diminution of elF4E activity suppresses parkin mutant phenotypes. Gene. 2011;470:12-9. https://doi.org/10.1016/j.gene.2010.09.003.

106. Imai Y, Gehrke S, Wang HQ, Takahashi R, Hasegawa K, Oota E, et al. Phosphorylation of 4E-BP by LRRK2 affects the maintenance of dopaminergic neurons in Drosophila. EMBO J. 2008;27:2432-43.

107. Tain LS, Mortiboys H, Tao RN, Ziviani E, Bandmann O, Whitworth AJ. Rapamycin activation of 4E-BP prevents parkinsonian dopaminergic neuron loss. Nat Neurosci. 2009;12:1129-35. https://doi.org/10.1038/nn.2372.

108. Meng H, Yamashita C, Shiba-Fukushima K, Inoshita T, Funayama M, Sato S, et al. Loss of Parkinson's disease-associated protein CHCHD2 affects mitochondrial crista structure and destabilizes cytochrome c. Nat Commun. 2017;8:1-18. https://doi.org/10.1038/ncomms15500.

109. Ferreira-Cerca S, Pöll G, Kühn H, Neueder A, Jakob S, Tschochner H, et al. Analysis of the in vivo assembly pathway of eukaryotic $40 \mathrm{~S}$ ribosomal proteins. Mol Cell. 2007;28:446-57.

110. Kim H, Son I, Seol W. Effect of leucine-rich repeat kinase 2 (LRRK2) on protein synthesis. Animal Cells Syst (Seoul). 2018;22:15-21.

111. Rouquette J, Choesmel V, Gleizes PE. Nuclear export and cytoplasmic processing of precursors to the 405 ribosomal subunits in mammalian cells. EMBO J. 2005:24:2862-72.

112. Ljungström V, Cortese D, Young E, Pandzic T, Mansouri L, Plevova K, et al. Whole-exome sequencing in relapsing chronic lymphocytic leukemia: clinical impact of recurrent RPS15 mutations. Blood. 2016;127:1007-16. https://doi.org/10.1182/blood-2015-10-674572.

113. Goudarzi KM, Lindström MS. Role of ribosomal protein mutations in tumor development (review). Int J Oncol. 2016;48:1313-24.

114. Martin I, Kim JW, Lee BD, Kang HC, Xu JC, Jia H, et al. Ribosomal protein s15 phosphorylation mediates LRRK2 neurodegeneration in parkinson's disease. Cell. 2014;157:472-85. https://doi.org/10.1016/.cell.2014.01.064.

115. Zhou ZD, Tan EK. Dopamine (DA) toxicity in pathogenesis and therapy of Parkinson's disease (PD). J Clin Bioanal Chem. 2017:1:1-3 http://www. alliedacademies.org/articles/dopamine-da-toxicity-in-pathogenesis-andtherapy-of-parkinsons-disease-pd-8683.html.

116. Manning C, Whyte DB, Martinez R, Hunter T, Sudarsanam S. The protein kinase complement of the human genome: EBSCOhost. Science. 2002;298: 1912-34. https://doi.org/10.1126/science.1075762.

117. Jaworski J, Sheng M. The growing role of mTOR in neuronal development and plasticity. Mol Neurobiol. 2006;34:205-219. doi:MN:34:3:205 [pii]\rhttps:// doi.org/10.1385/MN:34:3:205

118. Kwon C-H, Zhu X, Zhang J, Baker SJ. mTor is required for hypertrophy of Pten-deficient neuronal soma in vivo. Proc Natl Acad Sci. 2003;100:12923-8. https://doi.org/10.1073/pnas.2132711100.

119. Watanabe R, Wei L, Huang J. mTOR signaling, function, novel inhibitors, and therapeutic targets. J Nucl Med. 2011;1:497-501. https://doi.org/10.2967/ jnumed.111.089623.

120. Kim DH, Sarbassov DD, Ali SM, King JE, Latek RR, Erdjument-Bromage $H$, et al. mTOR interacts with raptor to form a nutrient-sensitive complex that signals to the cell growth machinery. Cell. 2002;110:163-75.

121. Goberdhan DCl, Wilson C, Harris AL. Amino acid sensing by mTORC1: intracellular transporters mark the spot. Cell Metab. 2016;23:580-9. https:/ doi.org/10.1016/j.cmet.2016.03.013.

122. Zoncu R, Efeyan A, Sabatini DM. MTOR: from growth signal integration to cancer, diabetes and ageing. Nat Rev Mol Cell Biol. 2011;12:21-35. https:// doi.org/10.1038/nrm3025.

123. Maiese K. Targeting molecules to medicine with MTOR, autophagy and neurodegenerative disorders. Br J Clin Pharmacol. 2016;82:1245-66.

124. Santini E, Heiman M, Greengard P, Valjent E, Fisone G. Inhibition of mTOR signaling in parkinson's disease prevents L-DOPA-induced dyskinesia. Sci Signal. 2009;2:1-11.

125. Malagelada C, Jin ZH, Jackson-Lewis V, Przedborski S, Greene LA. Rapamycin protects against neuron death in in vitro andln vivo models of Parkinson's disease. J Neurosci. 2010;30:1166-75. https://doi.org/10.1523/JNEUROSCl. 3944-09.2010.

126. Siracusa R, Paterniti I, Cordaro M, Crupi R, Bruschetta G, Campolo M, et al. Neuroprotective Effects of Temsirolimus in Animal Models of Parkinson's Disease. Mol Neurobiol. 2017;55:1-17.

127. Lu M, Su C, Qiao C, Bian Y, Ding J, Hu G. Metformin prevents dopaminergic neuron death in MPTP/P-induced mouse model of Parkinson's disease via autophagy and mitochondrial ROS clearance. Int J Neuropsychopharmacol. 2016;19:1-11. 
128. Ataie-Kachoie P, Pourgholami MH, Bahrami-B F, Badar S, Morris DL. Minocycline attenuates hypoxia-inducible factor-1a expression correlated with modulation of p53 and AKT/mTOR/p70S6K/4E-BP1 pathway in ovarian cancer: in vitro and in vivo studies. Am J Cancer Res. 2015;5:575-88. https:// www.ncbi.nIm.nih.gov/pubmed/25973298.

129. Ma J, Han LZ, Liang H, Mi C, Shi H, Lee JJ, et al. Celastrol inhibits the HIF-1a pathway by inhibition of mTOR/p70S6K/elF4E and ERK1/2 phosphorylation in human hepatoma cells. Oncol Rep. 2014;32:235-42.

130. Liu S, Lu B. Reduction of protein translation and activation of autophagy protect against PINK1 pathogenesis in drosophila melanogaster. PLoS Genet. 2010;6:1-12.

131. Lin W, Wadlington NL, Chen L, Zhuang X, Brorson JR, Kang UJ. Loss of PINK1 attenuates HIF-1 induction by preventing 4E-BP1-dependent switch in protein translation under hypoxia. J Neurosci. 2014;34:3079-89. https:// doi.org/10.1523/JNEUROSCI.2286-13.2014.

132. Qin $X$, Jiang $B$, Zhang Y. 4E-BP1, a multifactor regulated multifunctional protein. Cell Cycle. 2016;15:781-6. https://doi.org/10.1080/15384101.2016. 1151581.

133. Sanz FJ, Solana-Manrique C, Muñoz-Soriano V, Calap-Quintana P, Moltó MD, Paricio N. Identification of potential therapeutic compounds for Parkinson's disease using Drosophila and human cell models. Free Radic Biol Med. 2017;108:683-91. https://doi.org/10.1016/j.freeradbiomed.2017.04.364.

134. Frias MA, Thoreen CC, Jaffe JD, Schroder W, Sculley T, Carr SA, et al. mSin1 is necessary for Akt/PKB phosphorylation, and its isoforms define three distinct mTORC2s. Curr Biol. 2006;16:1865-70.

135. Conciatori F, Ciuffreda L, Bazzichetto C, Falcone I, Pilotto S, Bria E, et al, MTOR cross-talk in cancer and potential for combination therapy. Cancers (Basel). 2018;10:E23.

136. Kim LC, Cook RS, Chen J. MTORC1 and mTORC2 in cancer and the tumor microenvironment. Oncogene. 2017;36:2191-201. https:/doi.org/10.1038/ onc.2016.363.

137. Chuang CL, Lu YN, Wang HC, Chang HY. Genetic dissection reveals that Akt is the critical kinase downstream of LRRK2 to phosphorylate and inhibit FOXO1, and promotes neuron survival. Hum Mol Genet. 2014;23:5649-58.

138. Yerbury JJ, Ooi L, Dillin A, Saunders DN, Hatters DM, Beart PM, et al. Walking the tightrope: Proteostasis and neurodegenerative disease. J Neurochem. 2016;137:489-505

139. Lim J, Yue Z. Neuronal aggregates: formation, clearance, and spreading. Dev Cell. 2015:32:491-501. https://doi.org/10.1016/.jevcel.2015.02.002.

140. Lourenco MV, Ferreira ST, De Felice FG. Neuronal stress signaling and elF2a phosphorylation as molecular links between Alzheimer's disease and diabetes. Prog Neurobiol. 2015;129:37-57. https://doi.org/10.1016/j. pneurobio.2015.03.003.

141. Xu C, Bailly-Maitre B, Reed J. Endoplasmic reticulum stress: cell life and death decisions. J Clin Invest. 2005;115:2656-64. https://doi.org/10.1172/ JCl26373.2656.

142. Kim H, Strange K. Changes in translation rate modulate stress-induced damage of diverse proteins. AJP Cell Physiol. 2013;305:C1257-64. https://doi. org/10.1152/ajpcell.00176.2013.

143. Buffington SA, Huang W, Costa-Mattioli M. Translational control in synaptic plasticity and cognitive dysfunction. Annu Rev Neurosci. 2014;37:17-38. https://doi.org/10.1146/annurev-neuro-071013-014100.

144. Jousse C, Oyadomari S, Novoa I, Lu P, Zhang Y, Harding HP, et al. Inhibition of a constitutive translation initiation factor $2 a$ phosphatase, CReP, promotes survival of stressed cells. J Cell Biol. 2003;163:767-75.

145. Xu Y, Liu C, Chen S, Ye Y, Guo M, Ren Q, et al. Activation of AMPK and inactivation of Akt result in suppression of mTOR-mediated S6K1 and 4EBP1 pathways leading to neuronal cell death in in vitro models of Parkinson's disease. Cell Signal. 2014;26:1680-9. https://doi.org/10.1016/j. cellsig.2014.04.009.

146. Li Y, Zhang J, Yang C. UNC-51-like kinase 1 blocks S6k1 phosphorylation contributes to neurodegeneration in Parkinson's disease model in vitro. Biochem Biophys Res Commun. 2015;459:196-200. https://doi.org/10.1016/j. bbrc.2015.02.008.

147. Kapur M, Monaghan CE, Ackerman SL. Regulation of mRNA translation in neurons-a matter of life and death. Neuron. 2017;96:616-37. https://doi. org/10.1016/j.neuron.2017.09.057

\section{Ready to submit your research? Choose BMC and benefit from:}

- fast, convenient online submission

- thorough peer review by experienced researchers in your field

- rapid publication on acceptance

- support for research data, including large and complex data types

- gold Open Access which fosters wider collaboration and increased citations

- maximum visibility for your research: over $100 \mathrm{M}$ website views per year

At BMC, research is always in progress.

Learn more biomedcentral.com/submissions 